\title{
Procedures for computerized testing
}

\author{
MARK D. RECKASE \\ University of Missouri, Columbia, Missouri 65201
}

\begin{abstract}
The concept of tailored testing is defined in general terms and in terms of its major components: item calibration, item selection, and ability estimation. Each of the components is described and the available methods are summarized. The end result is a 12-category classification scheme based on the component parts. Four specific procedures are described. References are presented to suggest that the more adaptive procedures are capable of more precise measurement.
\end{abstract}

The purpose of this paper is to describe procedures that have used the computer for psychological testing and to summarize the results obtained in the areas of aptitude and achievement measurement.

Initially, computers were used as a substitute for the test booklet, that is, items were administered in the same order as the printed form; however, responses were recorded on a keyboard rather than on an answer sheet (Knights, Richardson, \& McNarry, 1973). Although this procedure controls many administration and environmental variables, it does not generally take advantage of the computer's computational capabilities. Current computerized testing procedures make full use of the power of the computer to tailor the test to each individual, further reducing errors due to the inappropriate difficulty of some test items. These procedures have been labeled tailored tests (Lord, 1970), adaptive tests (Weiss, 1974), response-contingent tests (Wood, 1973), and sequential tests (Krathwohl \& Huyser, 1956), among other things. This paper will concentrate on the tailored testing procedures that are currently being implemented.

\section{TAILORED TESTING}

Tailored testing is defined as an assessment technique that selects items from an item pool to match the capabilities of each individual being evaluated. The procedures developed to implement tailored testing attempt to estimate each person's ability, using a minimum number of appropriate items, while maintaining a high level of reliability, validity, and information (Lord \& Novick, 1968). The procedures not only aid in the control of test error, but also are more efficient in their use of examinee time and of test items.

Each of the many tailored testing procedures are made up of three components: (1) a procedure for determining the level of difficulty, and possibly the discrimination and susceptibility to guessing of the items placed in the item pool; (2) a procedure to select items from the item pool for administration to the examinees; and (3) a method to estimate the examinee's ability, based on the responses to the selected items. Each of these components will be described.

\section{Item-Calibration Procedures}

Item-calibration procedures are used to determine the characteristics of the items to be used in the item pool. These procedures are of the utmost importance in tailored testing, since the item-selection procedures are dependent upon the accuracy of the estimates of item characteristics in matching the items to the capabilities of the examinee. The procedures must be accurate and the results must be generalizable to the range of abilities likely to be measured using the tailored tests.

Three characteristics (item parameters) are often estimated in item calibration; many tailored testing procedures do not use all three. The parameters usually include indications of an item's difficulty, its ability to distinguish between different levels of performance (discrimination), and its susceptibility to guessing. The three calibration procedures used in tailored testing to estimate item parameters include: traditional methods, methods based on logistic models, and methods based on normal ogive models.

The traditional calibration procedures calculate estimates of the difficulty index (percent correct) and the discrimination index (correlation of item scores with the total test score) for each item. No estimate of the guessing probability for the item is obtained. Traditional methods have found limited application in tailored testing because the parameters estimated are too dependent on the particular sample on which they are determined. A few methods are based on these procedures (Cleary, Linn, \& Rock, 1968).

The other two calibration procedures used to estimate item parameters are based on item-characteristic curve theory (Lord \& Novick, 1968). A function, labeled an item-characteristic curve, is hypothesized to describe the relationship between the probability of getting an item correct and the ability of the examinee. The logistic (Birnbaum, 1968) and the normal ogive functions (Lord, 1952) are most often used for defining the item-characteristic curve. Calibration of an item pool based on these procedures amounts to estimating parameters that indicate the position, slope, and lower asymptote of the S-shaped curves defined by the functions. The position of the curve identifies the 
difficulty parameter of the item, the slope yields its discrimination parameter, and the lower asymptote yields the guessing parameter. Since the parameters based on item-characteristic curves are relatively sample independent, these calibration procedures have been used extensively. Some tailored testing procedures based on item-characteristic curve parameters do not use all of the estimates. For example, the Rasch model (Rasch, 1960), a special case of the logistic model, uses only the difficulty parameter.

\section{Item-Selection Procedures}

The item-selection procedure in tailored testing chooses the next item to be administered based on responses to previous items. It is this portion of the procedure that distinguishes tailored tests from traditional tests, where the next item is fixed, regardless of responses to previous items. Most techniques for selecting items fall into two broad classifications: structure based or model based.

Structure-based selection methods set up, in advance of the use of the procedure, an item-organization scheme based on the item-calibration data. The scheme is used to route examinees through the item pool. The itempool organization can be envisioned as a railway switching yard with items serving as switches. As a person responds to each item, the next item is selected, based upon the "track" to which the person is "switched." Sometimes the information for the decision points is obtained from one item, while in other procedures 2 to 20 items are used (Linn, Rock, \& Cleary, 1969). Once the original configuration is set, it is used for all examinees. For most structure-based procedures, items cannot be added or changed unless they are very similar to previously used items. Itempool sizes are also fixed in most cases by the procedure used. The major advantage of the structure-based procedures is their computational simplicity, but they suffer from lack of flexibility imposed by the fixed nature of the item-pool organization.

Model-based item-selection methods choose items to meet quality standards defined in terms of a mathematical model of test performance. Two techniques are commonly used: Items are selected to yield a specified probability of correct response for an examinee's estimated ability level; or items are selected to yield maximum information about an examinee's ability. In some cases, both criteria can be met simultaneously. Item pools for model-based procedures can vary in size and composition, as long as a minimum number of items are available to operate the procedure. The only organization imposed on the item pool is that needed for an efficient computer search. Model-based procedures typically require substantial computation in item selection, but are very flexible in the use of items.

\section{Ability-Estimation Procedures}

The ability-estimation procedures for tailored testing models use the responses to the selected items to estimate the performance level of examinees. The available procedures vary in complexity from the difficulty of the last item administered (Larkin \& Weiss, 1974) to the mean of a Bayesian posterior ability distribution (Jensema, 1974). The traditional "number correct" score is usually inappropriate, because each examinee may respond to different items and the number of items administered may differ from person to person. In this section, the many ability-estimation procedures are divided into tabulation and statisticalestimation procedures.

Tabulation procedures obtain an estimate of ability from a simple, sometimes arbitrary, function of the responses to items and the item parameters. Examples include the average difficulty of the items responded to correctly, the difficulty of the last item administered, and the difficulty of the item that would be administered next if the session were to continue (Lord, 1970). The possibilities are many and are limited only by the cleverness of the researcher. Research comparing the various tabulation procedures tends to support the use of average difficulty of items administered (Lord, 1970).

The statistical-estimation procedures obtain performance measures through the use of statisticalestimation techniques, such as least squares, maximum likelihood, and Bayesian. Maximum likelihood and Bayesian are the two models most often used. Maximum-likelihood estimation of ability seeks to find the ability estimate which yields the highest probability for the obtained response string. This may be done either empirically, searching for the mode of a likelihood distribution (Reckase, 1974a), or mathematically, finding the maximum by the derivative of the likelihood function.

The Bayesian procedures hypothesize a prior ability distribution and modify that distribution based on the item responses (Owen, 1975). The ability estimate is determined using a summary statistic, such as a mean or mode, of the resulting posterior ability distribution. Both the maximum-likelihood and Bayesian procedures require substantially more computation than do the tabulation procedures, but they also use more of the available information and yield estimates with more desirable mathematical properties.

\section{PROCEDURES}

Based on the categories of the three components of the tailored testing procedures (calibration, three types; item selection, two types; and ability estimation, two types), 12 different methods can be defined. Table 1 lists the levels of each of the three components and 
Table 1

Computerized Testing Procedures

\begin{tabular}{|c|c|c|c|}
\hline \multirow[b]{2}{*}{ Scoring Procedure } & \multirow[b]{2}{*}{ Calibration Procedure } & \multicolumn{2}{|c|}{ Item-Selection Procedure } \\
\hline & & Structure-Based & Model-Based \\
\hline \multirow{4}{*}{ Tabulation } & Traditional & $\begin{array}{l}\text { Brooks \& Kleinmuntz (1974) } \\
\text { Hansen, Johnson, Fagan, Tan, \& Dick (1975) } \\
\text { Knights, Richardson, \& McNarry (1973) } \\
\text { Linn, Rock, \& Cleary (1969) }\end{array}$ & Sixtl (1974) \\
\hline & Logistic & Wright \& Douglas (1975) & \\
\hline & Normal Ogive & $\begin{array}{l}\text { Betz \& Weiss }(1975) \\
\text { Larkin \& Weiss }(1974,1975) \\
\text { Lord }(1970) \\
\text { Vale \& Weiss }(1975) \\
\text { Weiss }(1973)\end{array}$ & \\
\hline & Traditional & $\begin{array}{l}\text { Cleary, Linn, \& Rock (1968) } \\
\text { Betz \& Weiss (1973) }\end{array}$ & Cliff (1975) \\
\hline \multirow[t]{2}{*}{ Statistical Estimation } & Logistic & & $\begin{array}{l}\text { Ireland }(1976) \\
\text { Reckase }(1974 \mathrm{a}, \mathrm{b}, \text { Note } 1) \\
\text { Urry }(1970) \\
\text { Jensema }(1974)\end{array}$ \\
\hline & Normal Ogive & Larkin \& Weiss (1975) & $\begin{array}{l}\text { Jensema (1974) } \\
\text { McBride (Note 2) } \\
\text { Owen (1969) } \\
\text { Samejima (Note 3) }\end{array}$ \\
\hline
\end{tabular}

gives references to the methods defined by each of the cells. The organization of the table is such that the simplest procedures (structure based, traditional, tabulation methods) are in the upper left corner and the procedures increase in complexity going both across and down. The model-based, normal ogive statistical-estimation procedures are the most complex. Space prohibits describing all of the procedures (interested readers may check the reference list), but some of the more prominent procedures will be discussed.

One of the earliest tailored testing procedures to attract interest is the two-stage test (Cleary, Linn, \& Rock, 1968). The procedure initially fell into the structure-based, traditional calibration, tabulation scoring category, but was later modified to use normal ogive parameters for item calibration. The procedure initially administers a short test of moderate difficulty, called a routing test, to all of the examinees. On the basis of scores on the routing test, examinees are administered one of several measurement tests. The measurement tests differ in difficulty and are designed to yield optimal measurement for a narrow range of ability. For example, a 10-item routing test might route those examinees with scores of 7-10 to the hardest measurement test, 4-6 to a measurement test of moderate difficulty, and $0-3$ to the easiest measurement test. Scores on the procedure are obtained using one of numerous procedures, including a weighted average of the ability estimates from the routing test and the measurement test (Larkin \& Weiss, 1975) and leastsquares estimates of longer traditional tests (Linn, Rock, \& Cleary, 1969).
A more adaptive procedure that uses structure-based item selection begins a testing session by administering an item of moderate difficulty. If a correct response is obtained, an item that is harder by a value $d$ is selected and administered. If a wrong response is obtained, an item that is easier by a value $d$ is selected and administered. After the second and subsequent items are administered, the process continues in the same way until a preset number of items have been administered. Since a diagram showing all of the possible paths through the item pool yields a triangular form, this procedure is often called a pyramidal test (Larkin $\&$ Weiss, 1974). The initial item is placed at the apex of the pyramid. Various methods are used for scoring, but one of the more desirable procedures is the average difficulty of the items administered, with difficulty determined from a normal ogive calibration.

A model-based procedure that uses maximumlikelihood estimation of logistic model parameters administers its initial items in much the same way as the pyramidal procedure (Reckase, 1974a). An item of moderate difficulty is administered first and the pyramidal item-selection method is used until both a correct and incorrect response are present. At that point, a maximum-likelihood estimate of ability is obtained, and the subsequent items are selected to have a .5 probability of a correct response for that ability level. Items are administered until sufficient accuracy is attained or until a preset limit is reached.

The most complex procedure now available for tailored testing is that based on the Bayesian procedure developed by Owen (1969). Initially a normal distribution is assumed as a prior belief of the distribution of 
ability. An item of moderate difficulty is selected for administration, and the prior distribution is modified on the basis of the response. The item pool is then searched for the item that provides the most information about the estimated ability level. That item is administered and subsequent items are selected in the same way. Item administration continues until the variance of the posterior distribution is sufficiently small or until a preset limit has been reached on the number of items.

The four tailored testing models presented here are a small sample of the many procedures that have been developed. Each of these has many variations, since they are constantly being modified as new research results become available. Therefore, the information presented should be taken only as a general orientation to the models, not as a precise description of their current operation.

\section{REVIEW OF TAILORED TESTING RESULTS}

The general trend of research findings in tailored testing indicates that the more adaptive the procedure, the more time and items that can be saved over traditional procedures without loss of precision of trait estimates. For example, Betz and Weiss (1973) and Linn, Rock, and Cleary (1969) studied tailored tests following the structure-based format and found that two-stage procedures, made up of a routing test and several measurement tests, generally gave reliabilities comparable to traditional tests of the same length, although the score distribution for the tailored tests more closely reflected the true score distribution. When using the more adaptive pyramidal (Linn, Rock, \& Cleary, 1969) and flexilevel tests (Betz \& Weiss, 1975), the reliabilities of the tailored tests were found to be higher than the traditional tests of equal length. Also, the correlations computed between the tailored tests and outside criteria were found to be larger than those for the traditional tests.

The model-based procedures give even better results. Jensema (1974), using simulation techniques, found that when 8 to 10 items were administered using a Bayesian logistic procedure, the correlation was about .90 with true ability. Similarly, Reckase (1974b) has found a maximum-likelihood logistic procedure to give reliabilities comparable to 50-item traditional tests, with adaptive tests averaging 11 items in length, although the correlations of the shorter tests with outside criteria were slightly lower. Numerous other studies also show this trend in reliability as the adaptive nature of the test increases.

\section{SUMMARY}

The purpose of this paper has been to summarize the concepts behind tailored testing methodology.
The components of the tailored testing procedures are described, along with a classification of the procedures into 12 possible combinations of the components. Finally, general trends in tailored testing research are described and emphasized with summaries of important research studies.

\section{REFERENCE NOTES}

1. Reckase, M. D. The effect of item-pool characteristics on the operation of a tailored testing procedure. Paper presented at the spring meeting of the Psychonomic Society, Murray Hill, New Jersey, 1976.

2. McBride, J. R. Some properties of a Bayesian sequential adaptive mental testing strategy. Paper presented at the Conference of Computerized Adaptive Testing, Washington, 1975.

3. Samejima, F. Behavior of the maximum likelihood estimate in a simulated tailored testing situation. Paper presented at the spring meeting of the Psychonomic Society, lowa City, Iowa, 1975.

\section{REFERENCES}

Betz, N. E., \& WeIss, D. J. An empirical study of computer administered two-stage ability testing. (Research Report 73-4). Minneapolis: Psychometric Method Program, University of Minnesota, October 1973. (NTIS No. AD 768993)

Betz, N. E., \& Weiss, D. J. Empirical and simulation studies of flexilevel ability testing. (Research Report 75-3). Minneapolis: Psychometric Methods Program, University of Minnesota, July 1975. (NTIS No. AD A013185)

Birngaum, A. Some latent trait models and their use in inferring an examinee's ability. In F. M. Lord \& M. R. Novick (Eds.), Statistical theories of mental test scores. Reading, Mass: Addison-Wesley, 1968. Chapters 17-20.

Brooxs, R., \& Kleinmuntz, B. Design of an intelligent computer psychodiagnostician. Behavioral Science, 1974, $19,16-20$.

Cleary, T. A., Linn, R. L., \& Rock, D. A. An exploratory study of programmed tests. Educational and Psychological Measurement, 1968, 28, 345-360.

ClIfF, N. Complete orders from incomplete data: Interactive ordering and tailored testing. Psychological Bulletin, 1975, 82, 289-302.

Hansen, D. N., Johnson, B. F., Fagan, R. L., Tan, D., \& Dick, W. Computer-based adaptive testing models for the Air Force technical training environment. Phase I: Development of a computerized measurement system for Air Force technical training. JSAS Catalog of Selected Documents in Psychology, 1975, 5(Ms. No. 882).

IRELAND, C. M. An application of the Rasch one-parameter logistic model to individual intelligence testing in a tailored testing environment. Unpublished doctoral dissertation, University of Missouri-Columbia, 1976.

JensmMa, C. J. The validity of Bayesian tailored testing. Educational and Psychological Measurement, $1974,34,757-766$.

Knigets, R. M., Richardson, D. H., \& MeNarry, L. R. Automated vs. clinical administration of the Peabody Picture Vocabulary Test and the Colored Progressive Matrices. American Journal of Mental Deficiency, 1973, 78, 223.225.

Krathwom, D. R., \& Huyser, R. J. The sequential item test (SIT). A merican Psychologist, 1956, 2, 419. (Abstract)

LARKIN, K. C., \& WEIss, D. J. An empirical investigation of computerassisted pyramidal ability testing (Research Report 74-3). Minneapolis: Psychometric Methods 
Program, University of Minnesota, July 1974. (NTIS No. AD 783553)

LARKIN, K. C.. \& WeIss, D. J. An empirical comparison of two-stage and pyramidal adaptive ability testing. (Research Report 75-1). Minneapolis: Psychometric Methods Program, University of Minnesota, February 1975. (NTIS No. AD A006733)

Linn, R. L., Rock, D. A., \& Cleary, T. A. The development and evaluation of several programmed testing methods. Educational and Psychological Measurement, $1969,29,129-146$.

Lord, F. M. A theory of test scores. Psychometric Monograph, 1952, 7, 1-84.

LoRd, F. M. Some test theory for tailored testing. In W. H. Holtzman (Ed.), Computer assisted instruction, testing, and guidance. New York: Harper \& Row, 1970.

LorD, F. M., \& Novick, M. R. Statistical theories of mental test scores. Reading, Mass: Addison-Wesley, 1968.

OWEN, R. J. A Bayesian approach to tailored testing. Research Bulletin (69-92). Princeton, N.J: Educational Testing Service, 1969.

OWEN, R. J. A Bayesian sequential procedure for quantal response in the context of adaptive mental testing. Journal of the American Statistical Association, 1975, 70, 351-356.

RASCH, G. Probabilistic models for some intelligence and attainment tests. Copenhagen: Denmarks Paedogogishe Institute, 1960.

RECKASE, M. D. An application of the Rasch simple logistic model to tailored testing. Paper presented at the 1974 Annual Meeting of the American Educational Research
Association, 1974. (ERIC Document Reproduction Service No. ED 092 585) (a)

RECKASE, M. D. An interactive computer program for tailored testing based on the one-parameter logistic model. Behavior Research Methods \& Instrumentation, 1974, 6, 208-212. (b)

Sixtr, F. Statistical foundations for a fully automated examiner. Zeitschrift fur Entwicklungspsychologie und Pädagogische Psychologie, 1974, 6, 28-38.

URRY, V. W. A Monte-Carlo investigation of logistic mental test models. Unpublished doctoral dissertation, Purdue University, 1970.

VALE, C. D., \& WEISs, D. J. A study of computeradministered stradaptive testing (Research Report 75-4). Minneapolis: Psychometric Methods Program, University of Minnesota, 1975. (NTIS No. AD A018758)

WeIss, D. J. The stratified adaptive computerized ability test (Research Report 73-3). Minneapolis: Psychometric Methods Program, University of Minnesota, 1973. (NTIS No. AD 768376)

WEIss, D. J. Strategies of adaptive ability measurement (Research Report 74-5). Minneapolis: Psychometric Methods Program, University of Minnesota, 1974. (NTIS No. AD A004270)

Wood, R. Response-contingent testing. Review of Educational Research, 1973, 43, 529-544.

WRIGHT, B. D., \& Douglas, G. A. Best test design and selftailored testing. (Research Memorandum No. 19). Chicago: University of Chicago, Statistical Laboratory, Department of Education, June 1975. 